Palavras chave:

Antioxidantes

Atividade enzimática

Estresse oxidativo

Viabilidade

Histórico:

Recebido |4/| |/20 | |

Aceito 10/12/2013

Keywords:

Antioxidants

Enzyme activity

Oxidative stress

Viability

Correspondência: elborges@ufv.br

DOI: | $0.1590 / 01047760201420031399$
Andressa Vasconcelos Flores', Eduardo Euclydes de Lima e Borges², Valéria Monteze Guimarães $^{2}$, José Francisco de Carvalho Gonçalves ${ }^{3}$, Glauciana da Mata Ataíde ${ }^{4}$, Daniela de Pádua Barros ${ }^{5}$

\section{ATIVIDADE ENZIMÁTICA DURANTE A GERMINAÇÃO DE SEMENTES DE Melanoxylon brauna Schott SOB DIFERENTES TEMPERATURAS}

RESUMO: Objetivou-se, com este trabalho, investigar o efeito da temperatura sobre o metabolismo oxidativo, por meio da atividade das enzimas superóxido dismutase (SOD), ascorbato peroxidase (APX) e catalase (CAT) no eixo embrionário e no endosperma micropilar de sementes de Melanoxylon brauna Schott, durante a germinação. As sementes foram semeadas em rolos de papel germitest umedecidos com água destilada e submetidas às temperaturas constantes de $15,25,30$ e $40^{\circ} \mathrm{C}$, durante 10 dias. As determinações das atividades das enzimas SOD, APX e CAT foram feitas nas sementes colocadas para germinar sob as mesmas condições descritas acima e a cada I 2 horas foram retiradas amostras até a protrusão radicular de $50 \%$ das sementes ou I 68 horas para a temperatura de $15^{\circ} \mathrm{C}$. Não foram detectadas atividades das enzimas SOD, APX e CAT no endosperma micropilar nas diferentes temperaturas. No eixo embrionário, as atividades das enzimas SOD e CAT apresentaram maiores alterações ao longo da germinação em $15^{\circ} \mathrm{C}$ e $40^{\circ} \mathrm{C}$, demonstrando que temperaturas estressantes provocam danos oxidativos. A atividade da enzima APX, no eixo embrionário, não foi afetada pela temperatura ao longo da germinação e sua atividade foi extremamente baixa.

\section{ENZYMATIC ACTIVITY DURING GERMINATION OF Melanoxylon brauna Schott AT DIFFERENT TEMPERATURES}

ABSTRACT: The objective of this study was to investigate the effect of temperature on the oxidative metabolism through the activity of the enzymes superoxide dismutase (SOD), ascorbate peroxidase (APX) and catalase (CAT) in the embryonic axis and micropylar endosperm of Melanoxylon brauna Schott seeds during germination. The seeds were sown in paper rolls germitest moistened with distilled water and subjected to constant temperatures of $15,25,30$ and $40^{\circ} \mathrm{C}$ for 10 days. Measurements of the activities of enzymes SOD, APX and CAT were made in the seeds germinated under the same conditions described above, and every 12 hours until the samples were taken root protrusion of $50 \%$ of the seeds or 168 hours for the temperature $15^{\circ} \mathrm{C}$. There were no activities of the enzymes SOD, APX and CAT in the micropylar endosperm at different temperatures. In the embryonic axis, the activities of the enzymes SOD and CAT showed greater changes over the germination of $15^{\circ} \mathrm{C}$ and $40^{\circ} \mathrm{C}$, demonstrating that temperature stress causes oxidative damage. The APX enzyme activity in the embryonic axis was not affected by temperature during germination and its activity was extremely low.

\footnotetext{
Universidade Federal de Santa Catarina - Curitibanos, Santa Catarina, Brasil

2 Universidade Federal de Viçosa - Viçosa, Minas Gerais, Brasil

3 Instituto Nacional de Pesquisas da Amazônia - Manaus, Amazonas, Brasil

4 Universidade Federal Rural do Rio de Janeiro - Seropédica, Rio de Janeiro, Brasil

5 Universidade Federal de Itajubá - Itajubá, Minas Gerais, Brasil
} 


\section{INTRODUÇÃO}

A germinação de sementes consiste na reativação do metabolismo e crescimento do embrião por meio de eventos metabólicos ordenados, cada um deles apresentando exigências próprias quanto à temperatura, principalmente porque dependem da atividade de sistemas enzimáticos específicos (BEWLEY; BLACK, 1994). No início da embebição ocorre aumento rápido na captação de oxigênio e na fosforilação oxidativa (TOMMASI et al., 200 I). Esta e a mobilização de reservas geram espécies reativas de oxigênio (EROs) que podem causar dano estrutural e funcional às células (PRODANOVIC et al., 2007). Os danos peroxidativos decorrem, principalmente, da deterioração oxidativa de ácidos graxos insaturados das membranas, pela ação de EROs presentes no interior das células. As espécies reativas de oxigênio incluem o oxigênio "singleto" ou molecular $\left(\mathrm{O}_{2}\right)$, peróxido de hidrogênio $\left(\mathrm{H}_{2} \mathrm{O}_{2}\right)$, radical superóxido $\left(\mathrm{O}_{2}^{-}\right)$e radical hidroxila $\left(\mathrm{OH}^{-}\right)$, dentre outros (SCANDALIOS, 1993).

Para que a célula não se deteriore por intoxicação, elas possuem eficiente mecanismo de enzimas removedoras de EROs (BAILLY, 2004; MCDONALD, 1999), incluindo as superóxidos dismutases (SOD, EC I.I5.I.I), peroxidases do ascorbato (APX, EC I.II.I.II), e a catalase (CAT, EC I.II.I.6) (MITTLER, 2003; SCANDALIOS, 2005). Dentro da célula, as superóxido dismutases constituem a primeira linha de defesa contra EROs (ALSCHER et al., 2002) e podem ser encontradas na matriz mitocondrial (MnSOD), citoplasma celular (Cu/ZnSOD) (ALSCHER et al., 2002; BOWLER et al., 1992; SCANDALIOS, 2005), sendo responsáveis por catalisar a dismutação do superóxido a peróxido de hidrogênio (MCDONALD, 1999; SCANDALIOS, 2005). A SOD produz $\mathrm{H}_{2} \mathrm{O}_{2}$ que, apesar de menos reativo, em altas concentrações tornase tóxico. O peróxido de hidrogênio é convertido em água pela ação da catalase, que está situada em glioxissomos e peroxissomos (SCANDALIOS, 2005; WILLEKENS et al., 1995). O ciclo da glutationa-ascorbato também pode eliminar parte do $\mathrm{H}_{2} \mathrm{O}_{2}$ e, para tanto, envolve, dentre outras, a enzima ascorbato peroxidase (BAILLY, 2004). As enzimas desse ciclo estão presentes nos cloroplastos, citoplasma, mitocôndria, peroxissomos e apoplastos (MITTLER, 2003) e aumentam sua atividade em resposta ao estresse oxidativo. Enzimas removedoras de EROs são consideradas de grande importância para a conclusão da germinação (BAILLY, 2004), tendo sido detectada durante a germinação de sementes de diversas espécies tais como: Triticum aestivum (CAKMAK et al., 1993),
Picea omorika (PRODANOVIC et al., 2007), Hordeum vulgare (MEI; SONG, 20I0), Medicago sativa (CAKMAK et al., 20I0) e Jatropha curcas (CAl et al., 20I I).

Melanoxylon brauna Schott, popularmente conhecida como braúna, braúna-preta, graúna, mariapreta, rabo-de-macaco cuja importância econômica, decorativa, fenologia e ocorrência encontram-se em Almeida et al. (1998), Barroso et al. (1999) e Lorenzi (2002). Apesar da importância ecológica e econômica da espécie, verifica-se que não há trabalho que aborda alterações fisiológicas e bioquímicas nos diferentes compartimentos das sementes durante a germinação sob diferentes temperaturas. Diante disso, objetivouse com este trabalho, investigar a atividade das enzimas superóxido dismutase, ascorbato peroxidase e catalase, durante a germinação no eixo embrionário e endosperma micropilar de sementes de Melanoxylon brauna sob diferentes temperaturas.

\section{MATERIAL E MÉTODOS}

\section{Material vegetal e beneficiamento}

As sementes de Melanoxylon brauna foram colhidas em 10 árvores-matrizes na cidade de Leopoldina - MG, em setembro de 2010. Os trabalhos foram conduzidos no Laboratório de Sementes Florestais do Departamento de Engenharia Florestal da Universidade Federal de Viçosa - UFV. Após a colheita, os frutos foram secos ao sol até sua abertura e as sementes, contendo aproximadamente $13 \%$ de teor de água, foram armazenadas em tamboretes de fibra de madeira, a $5^{\circ} \mathrm{C}$ e $60 \%$ de umidade relativa do ar. Durante o beneficiamento, foram eliminadas as sementes imaturas, deterioradas ou danificadas.

\section{Teste de germinação}

Para a determinação do percentual de germinação, as sementes foram semeadas em rolos de papel germitest umedecidos com água destilada (BRASIL, 2009), e submetidas às temperaturas (constantes) mínima $-15^{\circ} \mathrm{C}$, faixa ótima $-25^{\circ} \mathrm{C}$ e $30^{\circ} \mathrm{C}$ e máxima $-40^{\circ} \mathrm{C}$ (determinadas previamente) sob luz constante, durante 10 dias. Foram consideradas germinadas as sementes em que se constatou protrusão da radícula com $2 \mathrm{~mm}$. O número de sementes germinadas foi avaliado diariamente, sendo usado para o cálculo da porcentagem de germinação - G\% e o índice de velocidade de germinação - IVG (MAGUIRE, I962). O delineamento experimental utilizado foi o inteiramente casualizado e, 
em cada temperatura, foram realizadas cinco repetições de 20 sementes. Os dados foram submetidos à análise de variância e as médias comparadas pelo teste de Tukey, a $5 \%$ de probabilidade, utilizando-se o programa SAS (STATISTICAL ANALYSIS SYSTEM INSTITUTE - SAS INSTITUTE, 2002).

\section{Ensaios enzimáticos}

$\mathrm{Na}$ avaliação da atividade enzimática, as sementes foram semeadas conforme descrito anteriormente e, a cada 12 horas, foram retiradas amostras das sementes em que se constatou protrusão radicular de $50 \%$ das sementes ou 168 horas para a temperatura mínima $\left(15^{\circ} \mathrm{C}\right)$, conforme ensaios realizados anteriormente (dados não publicados), para a análise da atividade enzimática. Essas amostras foram armazenadas em freezer $\left(-20^{\circ} \mathrm{C}\right)$ até o momento das análises.

Os extratos enzimáticos brutos, usados para as determinações das atividades da superóxido dismutase (SOD), ascorbato peroxidase (APX) e catalase (CAT) foram obtidos a partir da metodologia descrita por Hodges et al. (1997), com pequenas adaptações. Amostras de 16 eixos embrionários e 16 endospermas micropilares foram separadamente trituradas, seguido da adição de 2,0 mL do seguinte meio de homogeneização: tampão fosfato $50 \mathrm{mM}, \mathrm{pH}$ 7,8 e polivinilpolipirrolidona (PVPP) $1 \%(p / v)$. Em seguida, o extrato foi centrifugado a $19.000 \times$ x durante 30 minutos, a $4{ }^{\circ} \mathrm{C}$, e o sobrenadante obtido foi utilizado como extrato enzimático bruto. Todo o procedimento foi feito sob baixa temperatura.

Atividade de SOD: A atividade da superóxido dismutase foi determinada pelo ensaio contendo $30 \mu \mathrm{L}$ do extrato enzimático bruto e $2,97 \mathrm{~mL}$ de um meio de reação constituído de: $1500 \mu \mathrm{L}$ de tampão fosfato de 100 $\mathrm{mM}, \mathrm{pH}$ 7,5, $780 \mu \mathrm{L}$ de metionina $50 \mathrm{mM}, 225 \mu \mathrm{L}$ de azul de p-nitro tetrazólio (NBT) I mM, $60 \mu \mathrm{L}$ de EDTA $5 \mathrm{mM}$, $60 \mu \mathrm{L}$ de riboflavina $2 \mu \mathrm{M}$ e $345 \mu \mathrm{L}$ de água destilada (DEL LONGO et al., 1993). A reação foi conduzida a $25^{\circ} \mathrm{C}$ em câmara de reação sob iluminação de uma lâmpada fluorescente de $15 \mathrm{~W}$. Após cinco minutos de exposição à luz, a iluminação foi interrompida e a formazana azul produzida pela fotorredução do NBT foi medida a $560 \mathrm{~nm}$ e a leitura obtida em $A_{560 \mathrm{~nm}}$ foi subtraída da amostra que recebeu iluminação (GIANNOPOLITIS; RIES, 1977). A absorbância a $560 \mathrm{~nm}$, de um meio de reação exatamente igual ao anterior, mas mantido no escuro, por igual tempo, foi usado como controle. Uma unidade de SOD foi definida como a quantidade da enzima necessária para inibir em $50 \%$ a fotorredução do NBT (BEAUCHAMP; FRIDOVICH, 197I).
Atividade de APX: A atividade da ascorbato peroxidase foi determinada pelo ensaio contendo $100 \mu \mathrm{L}$ do extrato enzimático bruto e $1400 \mu \mathrm{L}$ de um meio de reação constituído de $700 \mu \mathrm{L}$ de tampão de fosfato 50 $\mathrm{mM}, \mathrm{pH}$ 7,8, $400 \mu \mathrm{L}$ de ácido ascórbico 0,25 mM contendo EDTA 0,I mM, e $300 \mu \mathrm{L}$ de $\mathrm{H}_{2} \mathrm{O}_{2} 0,3 \mathrm{mM}$, adaptado de Ramalheiro (2009). O decréscimo na absorbância a $210 \mathrm{~nm}$, à temperatura de $25^{\circ} \mathrm{C}$, foi medido durante dois minutos com intervalo de 10 segundos entre cada leitura, sendo, a atividade da APX determinada com base na inclinação da reta após o início da reação. A atividade enzimática foi calculada utilizando-se o coeficiente de extinção molar de $2,8 \mathrm{mM} \cdot \mathrm{cm}^{-1}$ (NAKANO; ASADA, I98I). Uma unidade de atividade $(U)$ foi definida como a quantidade de enzima necessária para converter I nmol de substrato em produto por minuto, por $\mathrm{mL}$, nas condições do ensaio.

Atividade de CAT: A atividade da catalase foi determinada pelo ensaio contendo $100 \mu \mathrm{L}$ do extrato enzimático bruto e $1400 \mu \mathrm{L}$ de um meio de reação constituído de $900 \mu \mathrm{L}$ de tampão fosfato $50 \mathrm{mM}, \mathrm{pH}$ 7,8 e $500 \mu \mathrm{L}$ de $\mathrm{H}_{2} \mathrm{O}_{2}$ 0,97 M, adaptado de Hodges et al. (1997). O decréscimo na absorbância a 240 nm, à temperatura de $25^{\circ} \mathrm{C}$ foi medido durante dois minutos de reação a cada 10 segundos, sendo, a atividade da CAT determinada com base na inclinação da reta após o início da reação. A atividade enzimática foi calculada, utilizando-se o coeficiente de extinção molar de $36 \mathrm{M} \cdot \mathrm{cm}^{-1}$ (ANDERSON et al., 1995). Uma unidade de atividade (U) foi definida como a quantidade de enzima necessária para converter I $\mathrm{mmol}$ de substrato em produto por minuto, por $\mathrm{mL}$, nas condições do ensaio.

Os dados de determinação das atividades enzimáticas apresentados foram valores médios de ensaios em triplicata e os valores do desvio padrão foram calculados. As atividades enzimáticas foram expressas em atividade específica (SOD - U SOD $\mathrm{min}^{-1} \mathrm{mg} \mathrm{prot}^{-1}$; APX - nmol ASC min-1 $\mu \mathrm{g}$ prot $^{-1}$; CAT- mmol $\mathrm{H}_{2} \mathrm{O}_{2} \mathrm{~min}^{-1}$ $\mu \mathrm{g}$ prot $\left.^{-1}\right)$.

\section{Determinação da concentração de proteína}

A concentração de proteínas para todas as amostras foi determinada pelo método de Bradford (1976), utilizando-se curva padrão construída com albumina sérica bovina (BSA), de 2,5 a $50 \mu$ g de proteína.

\section{RESULTADOS E DISCUSSÃO}

Os resultados de germinação e IVG são observados na Tabela I. Sob temperatura de $15^{\circ} \mathrm{C}$, a germinação foi de apenas I I \%. Nas temperaturas de $25^{\circ} \mathrm{C}$ 
e $30^{\circ} \mathrm{C}$ as médias de germinação não diferiram entre si, observando-se o máximo de germinação. A germinação volta a decrescer na temperatura de $40^{\circ} \mathrm{C}$. Os valores de IVG aumentam significativamente com o aumento da temperatura até $30^{\circ} \mathrm{C}$, decrescendo significativamente em $40^{\circ} \mathrm{C}$. Percebe-se que $\circ$ aumento da temperatura até $30^{\circ} \mathrm{C}$ aumentou a velocidade de germinação, embora a porcentagem final não tenha diferenciado significativamente da observada a $25^{\circ} \mathrm{C}$. Como em qualquer sistema biológico, o aumento da temperatura resulta no aumento da velocidade das reações, tendo limites específicos para a progressão. Os resultados para Melanoxylon brauna diferem parcialmente daqueles apresentados por Bracalion et al. (20l0), em avaliação das diferentes temperaturas de germinação de espécies florestais brasileiras no bioma Mata Atlântica. Segundo os mesmos autores, a temperatura reflete o bioma original das sementes. No presente caso, a Melanoxylon brauna mostra amplitude de temperatura que é apropriada para a sua vasta região de ocorrência, do Pará a São Paulo.

TABELA I Germinação (\%) e índice de velocidade de germinação - IVG de sementes de Melanoxylon brauna submetidas a diferentes temperaturas.

TABLE I Germination and germination speed index of seeds of Melanoxylon brauna under different temperatures.

\begin{tabular}{ccc}
\hline Temperatura $\left({ }^{\circ} \mathrm{C}\right)$ & Germinação $(\%)$ & IVG \\
\hline 15 & $11 \mathrm{c}$ & $0,23 \mathrm{c}$ \\
25 & $90 \mathrm{a}$ & $3,22 \mathrm{~b}$ \\
30 & $89 \mathrm{a}$ & $4,13 \mathrm{a}$ \\
40 & $48 \mathrm{~b}$ & $3,31 \mathrm{~b}$ \\
\hline
\end{tabular}

Médias seguidas de mesma letra, nas colunas, não diferem entre si pelo teste de Tukey a $5 \%$.

Não foram detectadas, pela metodologia utilizada, atividade das enzimas SOD, APX e CAT no endosperma micropilar de sementes de Melanoxylon brauna, nas diferentes temperaturas. Esses resultados discordam dos observados no endosperma de sementes de Jatropha curcas, durante a germinação para as atividades das enzimas SOD e CAT (CAl et al., 20I I). Cakmak et al. (1993) também relatam a atividade das enzimas SOD, APX e CAT em endosperma de sementes de Triticum aestivum, porém, com valores inferiores aos observados no eixo embrionário. Entretanto, diferentes compartimentos das sementes comportam-se de maneira específica. Sementes de braúna submetidas ao envelhecimento acelerado a $45^{\circ} \mathrm{C}$ por 48 horas não apresentaram alterações significativas na atividade da SOD nos cotilédones, diferentemente do comportamento do eixo cuja atividade se alterou em 24 horas de envelhecimento (CORTE et al., 2010). Como o endosperma micropilar é composto por células de reserva, é de se esperar que não houvesse outra atividade que não a degradação das reservas, sem os mecanismos de proteção, caracterizados pelas enzimas de decomposição das EROs.

Os valores de atividade da SOD no eixo embrionário encontram-se na Figura I. Na temperatura de $15^{\circ} \mathrm{C}$, nas primeiras 12 horas de germinação, verificou-se diminuição da atividade da SOD, mantendose particularmente constante até próximo à protrusão da radícula, entre 156 e 168 horas, quando foi observado aumento da atividade (Figura la). Sob temperatura de 25,30 e $40^{\circ} \mathrm{C}$ a atividade dessa enzima decresceu a partir do tempo zero (testemunha) e manteve-se praticamente constante durante todo o período de germinação (Figura Ib, Ic e Id), demonstrando não sofrer influência das temperaturas durante a germinação, provavelmente por não serem temperaturas que causem estresse às sementes. Porém, a detecção da atividade da SOD ao longo desse processo sugere que ela esteja participando da proteção contra radicais superóxidos. Resultados semelhantes foram observados por Cakmak et al. (20l0) e Prodanovic et al. (2007), onde a atividade da enzima apresentou comportamento constante ao longo do período de germinação de semente de Picea omorika, sob temperatura de $25^{\circ} \mathrm{C}$, e de Medicago sativa, sob temperatura de $22^{\circ} \mathrm{C}$, respectivamente. Ressalta-se, que a atividade da enzima SOD, durante a germinação de sementes de Melanoxylon brauna é considerada alta, quando comparada aos resultados encontrados para outras espécies, durante a germinação de sementes (CAKMAK et al., I993; MEl; SONG, 20I0).

Detectou-se baixa atividade da enzima APX no eixo embrionário ao longo da germinação nas diferentes temperaturas (Figura 2), quando comparado à atividade da mesma enzima em diferentes tecidos de outras espécies (LOPES et al., 2009; MARINI et al., 20I3; ZHANG et al., 20I I), nos quais a unidade utilizada para expressar a atividade da APX é maior do que a utilizada neste trabalho. Analisando o comportamento da SOD e considerando que a APX é uma rota alternativa na retirada de peróxido de hidrogênio do meio, pode-se supor que a produção de EROs é baixa nessas sementes durante o processo de germinação, o que mantém a atividade desta enzima em níveis baixos. Esses resultados discordam dos observados por Mei e Song (2010), que verificaram aumento da atividade da enzima APX 

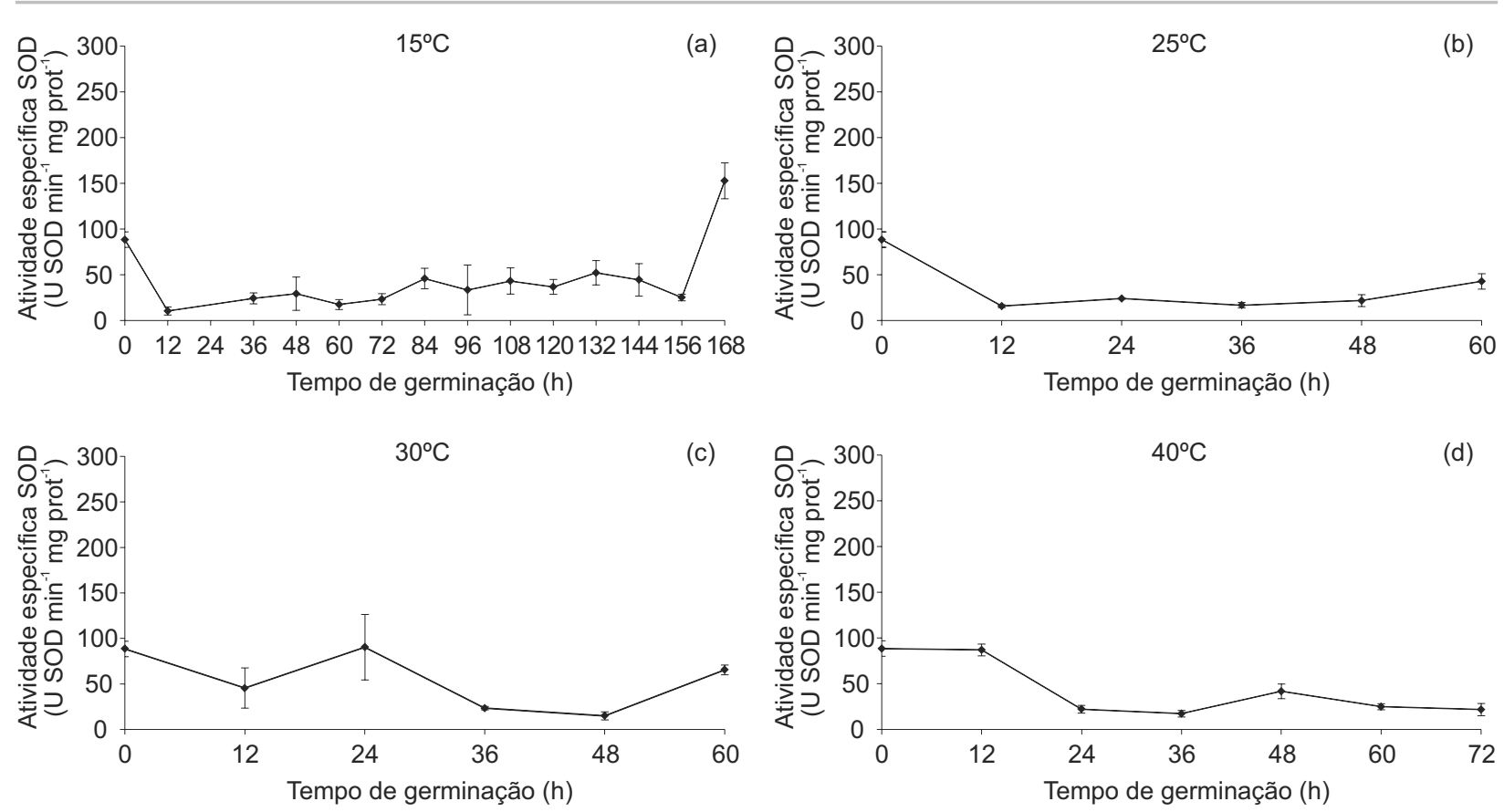

FIGURA I Atividade da enzima superóxido dismutase (SOD) no eixo embrionário durante o período de germinação de sementes de Melanoxylon brauna Schott sob efeito das temperaturas: a) $15^{\circ} \mathrm{C}$, b) $25^{\circ} \mathrm{C}$, c) $30^{\circ} \mathrm{C}$, d) $40^{\circ} \mathrm{C}$. Barras verticais indicam o valor do desvio padrão da média.

FIGURE I Activity of the superoxide dismutase enzyme (SOD) in the embryonic axis during germination of Melanoxylon brauna Schott under the influence of temperature: a) $15^{\circ} \mathrm{C}$, b) $25^{\circ} \mathrm{C}$, c) $30^{\circ} \mathrm{C}$, d) $40^{\circ} \mathrm{C}$. Vertical bars indicate the mean standard deviation.
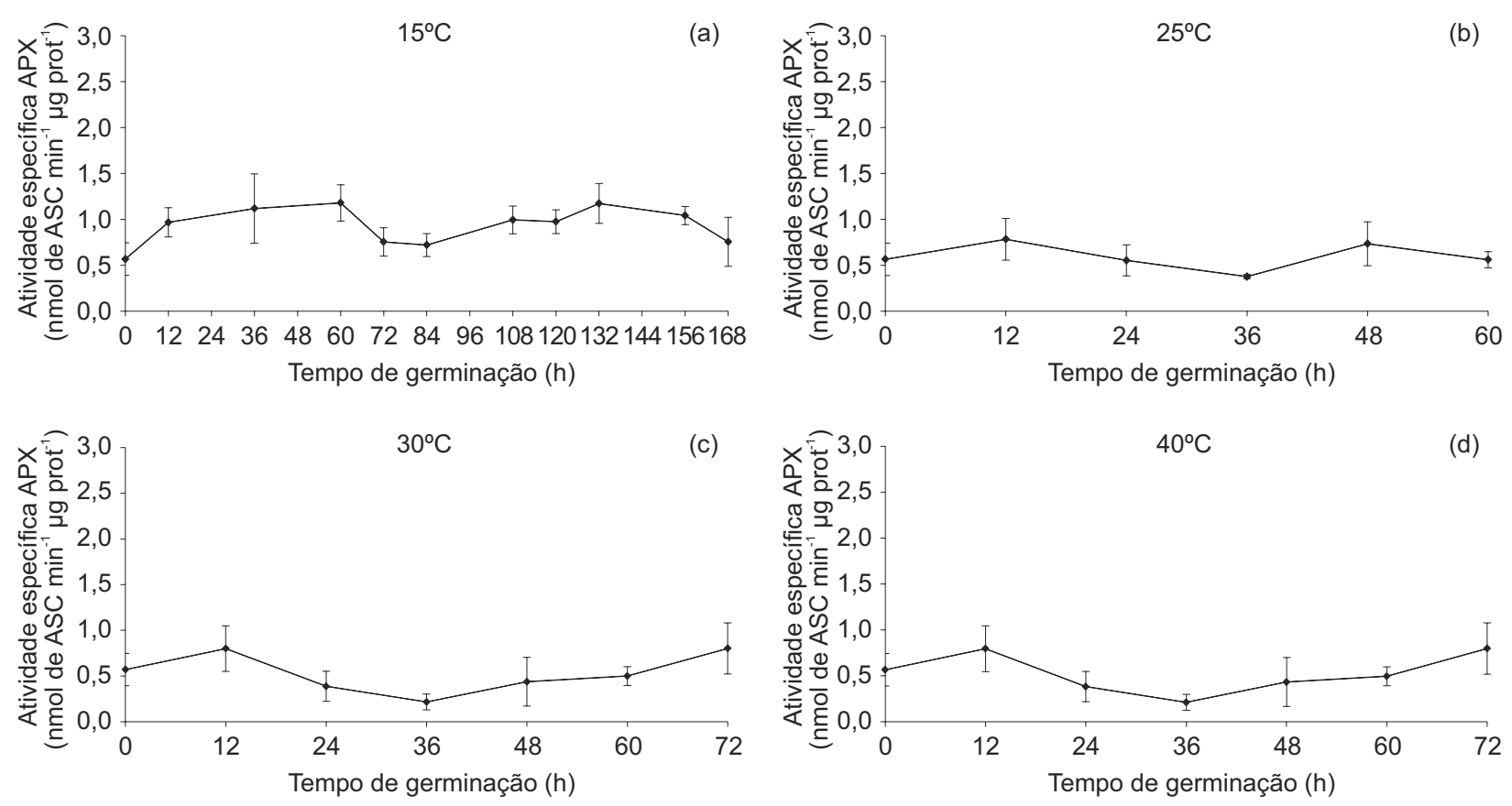

FIGURA 2 Atividade da enzima ascorbato peroxidase (APX) no eixo embrionário durante o período de germinação de sementes de Melanoxylon brauna Schott sob efeito das temperaturas: a) $15^{\circ} \mathrm{C}$, b) $25^{\circ} \mathrm{C}$, c) $30^{\circ} \mathrm{C}$, d) $40^{\circ} \mathrm{C}$. Barras verticais indicam o valor do desvio padrão da média.

FIGURE 2 Activity of the ascorbate peroxidase enzyme (APX) in the embryonic axis during germination of Melanoxylon brauna Schott under the influence of temperature: a) $15^{\circ} \mathrm{C}$, b) $25^{\circ} \mathrm{C}$, c) $30^{\circ} \mathrm{C}$, d) $40^{\circ} \mathrm{C}$. Vertical bars indicate the mean standard deviation. 
em sementes de Hordeum vulgare com a elevação da temperatura de 0 a $25^{\circ} \mathrm{C}$ e decréscimo da atividade a partir dessa temperatura. Ramalheiro (2009) também verificou aumento na atividade da enzima em algumas variedades de Olea europaea, em diferentes estádios de maturação e afirmou que esse comportamento pode significar importante capacidade da espécie em desenvolver mecanismos de tolerância ao estresse, especialmente no combate as EROs.

A CAT apresentou pequenas alterações na sua atividade ao longo da germinação, sob diferentes temperaturas (Figura 3), cujos níveis foram mais baixos que o da APX. Nas temperaturas de $15^{\circ} \mathrm{C}$ (Figura 3a) observa-se aumento na atividade ao longo da germinação, a partir de 84 horas, demonstrando que há produção de $\mathrm{H}_{2} \mathrm{O}_{2}$ nas células. $A$ atuação das rotas envolvendo a APX e CAT são concomitantes, o que pode resultar na baixa atividade de ambas, mas com provável eficiente desempenho de desintoxicação. $\mathrm{Na}$ temperatura de $25^{\circ} \mathrm{C}$, observa-se pequeno declínio nas primeiras 24 horas e aumento a partir de 36 horas, quando atingiu valores próximos ao da testemunha em 60 horas. Em $30^{\circ} \mathrm{C}$ houve redução da atividade nas primeiras 12 horas, permanecendo constante e em valores próximos àqueles de $25^{\circ} \mathrm{C}$. Sob $40^{\circ} \mathrm{C}$ o comportamento foi semelhante ao de $25^{\circ} \mathrm{C}$ nas primeiras 36 horas, mas com elevação em 48 horas, permanecendo estável a seguir. Considerando que $15^{\circ} \mathrm{C}$ e $40^{\circ} \mathrm{C}$ foram temperaturas fora da faixa ótima de germinação, é razoável supor situação de estresse influenciando a maior atividade da enzima. Cakmak et al. (20l0) observaram diminuição da atividade da enzima CAT ao longo da germinação de Medicago sativa, sob temperatura de $22^{\circ} \mathrm{C}$. Pode-se concluir, que o comportamento da enzima CAT durante - processo de germinação é intrínseco a cada espécie. Segundo Mei e Song (2010), os aumentos nas atividades de enzimas removedoras de EROs podem ser um elemento comum durante a germinação de sementes que possuem mecanismos de tolerância ao estresse. Para Prodanovic et al. (2007), as atividades das enzimas SOD e CAT podem estar envolvidas na preservação da viabilidade e proteção das membranas das sementes contra as EROs produzidas durante a germinação. Huang e Guo (2005), em estudo com duas cultivares de Oryza sp. (Xiangnuo-I e IR-50), uma tolerante e outra não tolerante ao resfriamento, observaram que as atividades das enzimas SOD, APX e CAT se mantiveram alta na cultivar tolerante, quando submetidas à temperatura de $8^{\circ} \mathrm{C}$, e decresceu na cultivar não tolerante, nessa mesma condição. Os autores concluíram que a atividade mais alta das enzimas antioxidantes está associada à tolerância da cultivar à baixa temperatura.
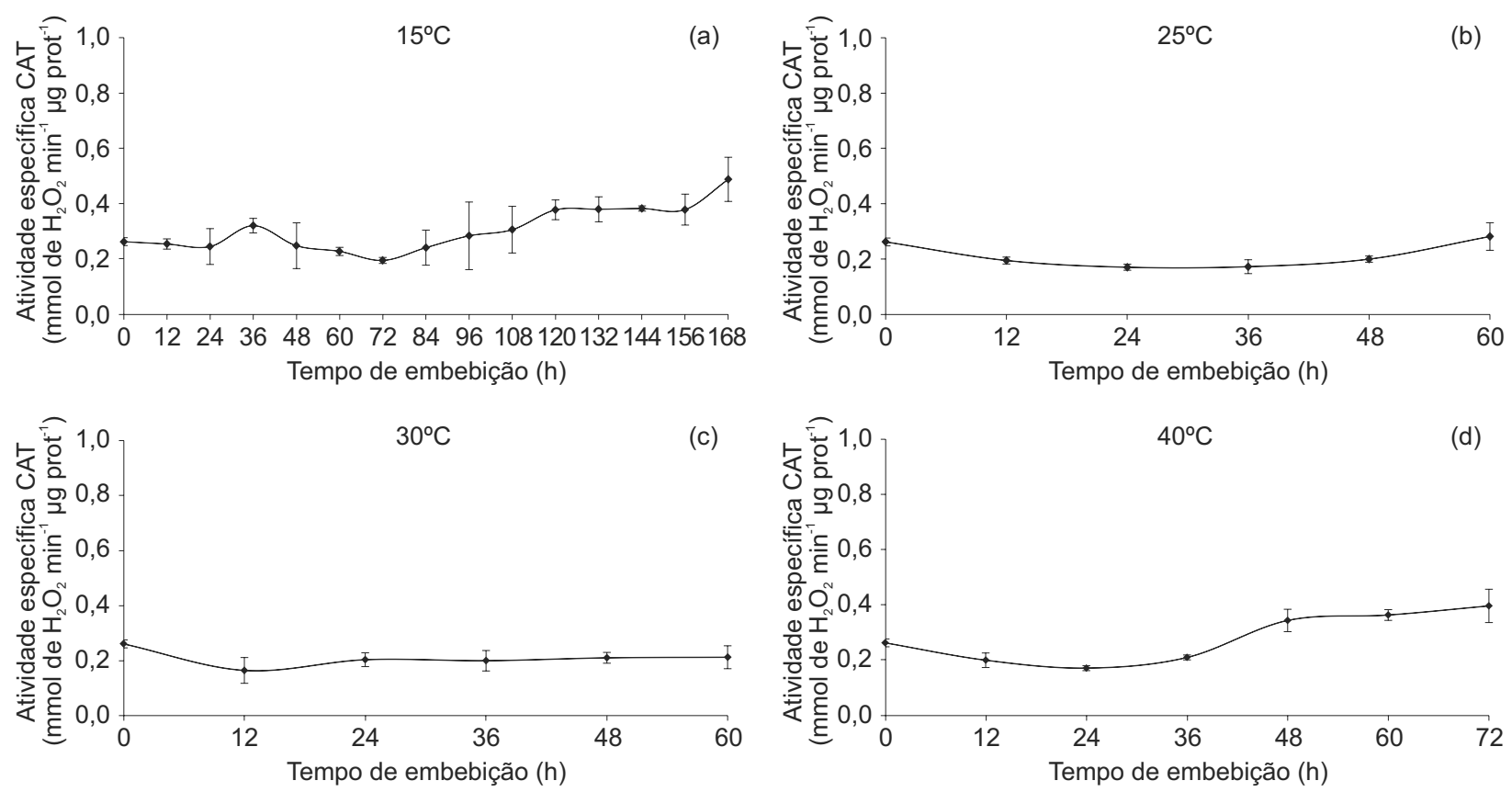

FIGURA 3 Atividade da enzima catalase (CAT) no eixo embrionário durante o período de germinação de sementes de Melanoxylon brauna Schott sob efeitos das temperaturas: a) $15^{\circ} \mathrm{C}$, b) $25^{\circ} \mathrm{C}$, c) $30^{\circ} \mathrm{C}$, d) $40^{\circ} \mathrm{C}$. Barras verticais indicam o valor do desvio padrão da média.

FIGURE 3 Activity of the catalase enzyme (CAT) in the embryonic axis during germination of Melanoxylon brauna Schott under the influence of temperature: a) $15^{\circ} \mathrm{C}$, b) $25^{\circ} \mathrm{C}$, c) $30^{\circ} \mathrm{C}$, d) $40^{\circ} \mathrm{C}$. Vertical bars indicate the mean standard deviation. 


\section{CONCLUSÕES}

As atividades das enzimas SOD, APX e CAT não são detectadas no endosperma micropilar de sementes de Melanoxylon brauna, sob diferentes temperaturas. As enzimas SOD e CAT apresentam maiores alterações em suas atividades no eixo embrionário em $15^{\circ} \mathrm{C}$ e $40^{\circ} \mathrm{C}$. A atividade da enzima APX no eixo embrionário é baixa, não sendo afetada pela temperatura para a espécie em estudo.

\section{REFERÊNCIAS}

ALMEIDA, S. P.; PROENÇA, C. E. B.; SANO, S. M.; RIBEIRO, J. F. Cerrado: espécies vegetais úteis. Planaltina: EMBRAPACPAC, 1998. 464 p.

ALSCHER, R. G.; ERTURK, N.; HEATH, L. S. Role of superoxide dismutases (SODs) in controlling oxidative stress in plants. Journal of Experimental Botany, Oxford, v. 53, p. |33||34I, 2002.

ANDERSON, M. D.; PRASAD, T. K.; STEWART, C. R. Changes in isozyme profiles of catalase, peroxidase, and glutathione reductase during acclimation to chilling in mesocotyls of maize seedlings. Plant Physiology, Bethesda, v. 109, p. |247-| 257, 1995.

BAILLY, C. Active oxygen species and antioxidants in seed biology. Seed Science Research, Wallingford, v. 14, n. 2, p. 93-107, 2004.

BARROSO, G. M.; MORIM, M. P.; PEIXOTO, A. L.; ICHASO, C. L. F. Frutos e sementes: morfologia aplicada à sistemática de dicotiledôneas. Viçosa, MG: UFV, 1999. 443 p.

BEAUCHAMP, C.; FRIDOVICH, I. Superoxide dismutase improved as says and as say applicable to acrylamide gels. Analytical Biochemistry, New York, v. 44, p. 276-287, 1971.

BEWLEY, J. D.; BLACK, M. Seeds: physiology of development and germination. $2^{\text {nd }}$ ed. New York: Plenum, 1994. 445 p.

BOWLER, C.; MONTAGU, M. van; INZÉ, D. Superoxide dismutase and stress tolerance. Annual Review of Plant Physiology and Plant Molecular Biology, Palo Alto, v. 43, p. 83-II6, 1992.

BRADFORD, M. M. A rapid and sensitive method for the quantification of microgram quantities of proteins utilizing the principle of protein-dye binding. Analytical Biochemistry, New York, v. 72, p. 248-254, 1976.

BRANCALION, P. H. S.; NOVEMBRE, A. D. L. C.; RODRIGUES, R. R. Temperatura ótima de germinação de sementes de espécies arbóreas brasileiras. Revista Brasileira de Sementes, Brasília, v. 32, n. 4, p. 15-2I, 2010.
BRASIL. Ministério da Agricultura, Pecuária e Abastecimento. Regras para análise de sementes. Brasília, 2009. 399 p.

CAI, F.; MEI, L.; AN, X.; GAO, S.; TANG, L.; CHEN, F. Lipid peroxidation and antioxidant responses during seed germination of Jatropha curcas. Journal of Agriculture and Biology, Oxford, v. 13, p. 25-30, 2011.

CAKMAK, T.; ATICI, O.; AGAR, G.; SUNAR, S. Natural agingrelated biochemical changes in alfafa (Medicago sativa L.) seeds stored for 42 years. International Research Journal of Plant Science, Amsterdam, v. I, n. I, p. I-6, 2010.

CAKMAK, I.; STRBAC, D.; MARSCHNER, H. Activities of hydrogen peroxide-scavening enzymes in germinating wheat seeds. Journal of Experimental Botany, Oxford, v. 44, n. 258 , p. 127-132, 1993.

CORTE, V. B.; BORGES, E. E. L.; LEITE, H. G.; PEREIRA, B. C.; GONÇALVES, J. F. C. Estudo enzimático da deterioração de sementes de Melanoxylon brauna submetidas ao envelhecimento natural e acelerado. Revista Brasileira de Sementes, Brasília, v. 32, n. I, p. 83-9I, 2010.

DEL LONGO, O. T.; GOINZ'ZZEZ, C. A.; PASTORI, G. M.; TRIPPI, V. S. Antioxidant defenses under hyperoxygenic and hyperosmotic conditions in leaves of two lines of maize with differential to drought. Plant Cell Physiology, Oxford, v. 37, n. 7, p. 1023-1028, 1993.

GIANNOPOLITIS, C. N.; RIES, S. K. Superoxide dismutases: I., occurrence in higher plants. Plant Physiology, Bethesda, v. 59, p. 309-3।4, 1977.

HODGES, D. M.; ANDREWS, C. J.; JOHNSON, D. A.; HAMILTON, R. I. Antioxidant enzyme responses to chilling stress in differentially sensitive inbred maize lines. Journal of Experimental Botany, Oxford, v. 48, n. 310, p. II05III3, 1997.

HUANG, M.; GUO, Z. Responses of antioxidative system to chilling stress in two Rice cultivars differing in sensitivy. Biology Plantarum, Copenhagen, v. 49, n. I, p. 8I-84, 2005.

LOPES, A. M.; CUCHIARA, C. C.; BORGES, C. de S.; DEUNER, S.; SILVA, S. D. dos A.; BOBROWSKI, V. L. Efeitos da radiação cobalto-60 sobre o metabolismo das enzimas antioxidativas em plântulas de mamona (Ricinus communis L.). In: CONGRESSO DE INICIAÇÃO CIENTíFICA, I8.; ENCONTRO DE PÓS GRADUAÇÃO, II.; MOSTRA CIENTíFICA, I., 2009, Pelotas. Anais... Pelotas: UFPEL, 2009. I CD-ROM.

LORENZI, H. Árvores brasileiras: manual de identificação e cultivo de plantas arbóreas do Brasil. Nova Odessa: Instituto Plantarum, 2002. v. I, 368 p. 
MAGUIRE, J. D. Speed of germination and in selection and evaluation from seeding emergence and vigor. Crop Science, Madison, v. 2, n. 2, p. 176-177, 1962.

MARINI, P.; BANDEIRA, J. de M.; BORBA, I. C. G. de; MARTINS, A. B. N.; MORAES, D. M. de; AMARANTE, L. do; VILLELA, F. A. Antioxidant activity of corn seeds after thermal stress. Ciência Rural, Santa Maria, v. 43, n. 6, p. 95I-956, jun. 2013.

MCDONALD, M. B. Seed deterioration: physiology, repair and assessment. Seed Science and Technology, Zurich, v. 27, n. I, p. 177-237, 1999.

MEI, Y.; SONG, S. Response to temperature stress of reactive oxygen species scavengig enzymes in the cross-tolerance of barley seed germination. Journal of Zhejiang UniversityScience B (Biomedicine \& Biotechnology), Hangzhou, v. II, n. 12, p. 965-972, 2010.

MITTLER, R. Oxidative stress, antioxidants and stress tolerance. Trends in Plant Science, Oxford, v. 7, n. 9, p. 405-4 I0, Sept. 2003.

NAKANO, Y.; ASADA, K. Hydrogen peroxide is scavenged by ascorbate-specific peroxidase in spinach chloroplasts. Plant Cell Physiology, Oxford, v. 22, n. 5, p. 867-880, I98I.

PRODANOVIĆ, O.; PRODANOVIĆ, R.; BOGDANOVIĆ, J.; MITROVIĆ, A.; MILOSAVIĆ, N.; RADOTIĆ, K. Antioxidative enzymes during germination of two lines of serbian spruce [Picea omorika (Panč.) Purkyně]. Archives of Biological Sciences, Oxford, v. 5, n. 3, p. 209-2I6, 2007.
RAMALHEIRO, J. P. S. C. Contribuição para a caracterização bioquímica do estado de maturação de azeitonas de diferentes variedades. 2009. 5 I p. Dissertação (Mestrado em Engenharia Alimentar) - Universidade Técnica de Lisboa, Lisboa, 2009.

SCANDALIOS, J. G. Oxygen stress and superroxides dismutases. Plant Physiology, Bethesda, v. I0I, p. 7-12, 1993.

SCANDALIOS, J. G. Oxidative stress: molecular perception and transduction of signals triggering antioxidant gene defenses. Brazilian Journal of Medical and Biological Research, Ribeirão Preto, v. 38, p. 995-1014, 2005.

STATISTICAL ANALYSIS SYSTEM INSTITUTE. SAS: getting started with the SAS learning edition. Cary, 2002. 86 p.

TOMMASI, F.; PACIOLLA, C.; PINTO, M. C.; GARA, L. A. Comparative study of glutathione and ascorbate metabolism during germination of Pinus pinea L. seeds. Journal Experimental Botany, Oxford, v. 52, p. 647I654, 200|

WILLEKENS, H. I. D.; MONTAGU, M. van; CAMP, W. van. Catalases in plants. Molecular Breeding, Dordrecht, v. I, p. 207-228, 1995.

ZHANG, S.; JIANG, H.; PENG, S.; KORPELAINEN, H.; LI, C. Sex-related differences in morphological, physiological, and ultrastructural responses of Populus cathayana to chilling. Journal of Experimental Botany, Oxford, v. 62, n. 2, p. 675-686, 2011 